\title{
Cigarette Smoke Extract Exposure: Effects on the Interactions between Titanium Surface and Osteoblasts
}

\author{
Jie Yang, ${ }^{1,2}$ Shui-yi Shao,, ${ }^{1,2}$ Wan-qing Chen, ${ }^{1,2}$ Chao Chen, ${ }^{3}$ \\ Song-mei Zhang, ${ }^{4}$ and Jing Qiu (iD ${ }^{1,2}$ \\ ${ }^{1}$ Department of Oral Implantology, Affiliated Hospital of Stomatology, Nanjing Medical University, Nanjing 210029, China \\ ${ }^{2}$ Jiangsu Key Laboratory of Oral Disease, Nanjing Medical University, Nanjing 210029, China \\ ${ }^{3}$ Department of Oral Implantology, Huaxia Hospital of Stomatology, Suzhou, China \\ ${ }^{4}$ Department of General Dentistry, University of Rochester Eastman Institute for Oral Health, Rochester, NY, USA
}

Correspondence should be addressed to Jing Qiu; qiujing@njmu.edu.cn

Received 4 February 2019; Revised 22 March 2019; Accepted 8 April 2019; Published 22 April 2019

Academic Editor: Konstantinos Michalakis

Copyright (c) 2019 Jie Yang et al. This is an open access article distributed under the Creative Commons Attribution License, which permits unrestricted use, distribution, and reproduction in any medium, provided the original work is properly cited.

\begin{abstract}
The aim of this study was to explore the changes in the characteristics of titanium surface and the osteoblast-titanium interactions under cigarette smoke extract (CSE) exposure. In this study, CSE was used to simulate the oral liquid environment around the implant under cigarette smoke exposure. Titanium samples were immersed in CSE to explore the changes in the characteristics of titanium surface. The physical properties of titanium surface were measured, including surface micromorphology, surface elemental composition, roughness, and surface hydrophilicity. MC3T3-E1 cells were cultured on the titanium surface in vitro under different concentrations of CSE exposure, and cell adhesion, cell proliferation, and osteogenic differentiation were observed. The surface micromorphology and elemental composition of titanium surface changed under CSE exposure. No obvious changes were found in the surface roughness and the hydrophilicity of titanium samples. Moreover, the results of in vitro study showed that CSE exposure downregulated the cell spreading, proliferation, and osteogenic differentiation of MC3T3-E1 cells on the titanium surface. It could be speculated that some carbon-containing compounds from CSE adsorbed on the titanium surface and the osteoblast-titanium interactions were influenced under CSE exposure. It is hoped that these results could provide valuable information for further studies on smoking-mediated inhibition of implants osseointegration.
\end{abstract}

\section{Introduction}

Smoking is common in modern civilization. The estimated prevalence of daily tobacco smoking among the adult population was $15.2 \%$ [1]. Tobacco is the single leading and preventable cause of death worldwide [2]. Smoking is related to several systemic diseases [3-5]. It has also been regarded as a major risk factor that triggers the development of oral diseases [6]. As is well known, despite high success rate, dental implant failures occur occasionally. Smoking is considered as one of the major risk factors for the failure of dental implants [7-10]. Clinical studies revealed that smoking could affect initial implant survival rates and early osseointegration [11-14]. In fact, cigarette smoke is a highly dynamic complex consisting of more than 3800 compounds, including oxidants, nicotine, heavy metals, aromatic hydrocarbons, and aldehydes $[15,16]$. Although the components of cigarette smoke have been identified, the mechanism of its effect on the osseointegration between bone and dental implant is still unclear.

In recent years, dental implant technology has been developed continuously $[17,18]$. Dental rehabilitation of partially or totally edentulous patients with dental implants has become a common practice in the past decades [19]. Dental implants play an important role in the dental restoration [20]. Titanium is commonly used for dental implants because of its excellent biocompatibility and satisfactory mechanical properties. Osseointegration is crucial to the dental implant technology $[21,22]$. Osseointegration is defined as "the firm, direct, and lasting biological attachment of a metallic implant to vital bone without intervening connective tissue" by the American Academy of Implant Dentistry. Dental implants 
fail mostly because of an incomplete establishment of the bone-implant interface [23]. From a biochemical perspective, it is well accepted that hydrocarbons from the atmosphere, water, or cleaning solution could adsorb on the titanium surfaces [24]. A previous study reported that osteoblast attachment to titanium surfaces was inversely correlated with the hydrocarbon adsorption on titanium surfaces [25]. It provides us with a new way of thinking that substances adsorption on the titanium surface may account for the failure of osseointegration.

Could the substances of cigarette smoke adsorb on the implant surface? Some studies reported that implants were exposed to the oral cavity in the early process of osseointegration [26-29]. In addition, smoking could inhibit the healing of gingiva and the function of gingival fibroblasts $[20,30]$ and even increased the incidence of implant exposure [7, 9]. In the case of nonsubmerged healing, the interface between implant and bone is directly exposed to the oral cavity. In the case of submerged healing, spontaneous implant exposure does exist and could account for crestal bone loss around the dental implant during the early osseointegration phase [31]. Tal et al. reported that the spontaneous early exposure rate of submerged implants could reach as high as $13.7 \%$ [26]. Thus, substances of cigarette smoke might adsorb on the implant through the exposure of dental implants in the oral cavity. It could be speculated that cigarette smoke could affect the early osseointegration of the implant through its exposure.

Up to date, the exact mechanism underlying the smokingmediated inhibition of the osseointegration remains to be elucidated. To the best of the authors' knowledge, little attention has been paid to the influence of the cigarette smoke on both titanium implant surface and osteoblast behavior. We hypothesized that cigarette smoke exposure could influence the interaction between titanium surface and osteoblast. In the present study, preliminary model for investigating the effects of cigarette smoke on the osseointegration of titanium implants was provided. Cigarette smoke extract (CSE) was commonly used to simulate smoking in the study of pulmonary diseases in vitro [32], culturing human lung fibroblasts [33], pulmonary epithelial cell [34], and primary nasal epithelial cells [35]. In this work, CSE is used to simulate the oral liquid environment around the implant under cigarette smoke exposure [36]. We sought to evaluate the effect of CSE exposure on the characteristics of titanium surface and the role of CSE exposure on osteoblasttitanium interactions. We hope that the results would provide valuable information for exploring the initiating causes of the smoking-mediated inhibition of the osseointegration.

\section{Materials and Methods}

2.1. CSE Preparation. As shown in Figure 1, CSE was freshly prepared by bubbling the smoke drawn from a lit cigarette (nicotine $0.8 \mathrm{mg}$, tar $11 \mathrm{mg}$, Marlboro, China) through 10 $\mathrm{mL}$ prewarmed $\left(37^{\circ} \mathrm{C}\right)$ cell culture medium $(\alpha$-MEM, Gibco, USA) [37]. The cigarette was smoked at a rate of $50 \mathrm{~mL}$ over a period of $2 \mathrm{~s}$, followed by a $28 \mathrm{~s}$ pause, matching the smoking habits of an average smoker [38]. The obtained extract was filtered through a $0.22 \mu \mathrm{m}$ pore filter (Millipore, Bedford, MA,

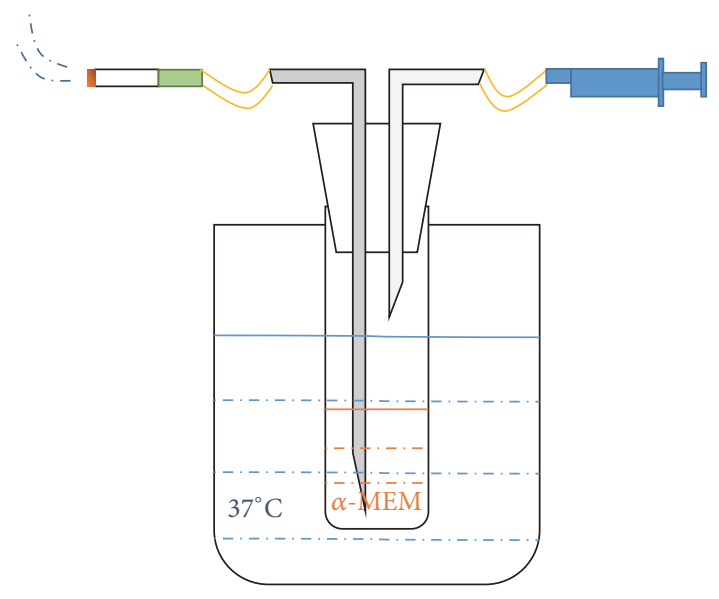

FIGURE 1: Schematic representation of the CSE-generating machine. CSE was freshly prepared by bubbling the smoke drawn from a commercially available cigarette through $10 \mathrm{~mL}$ prewarmed $\left(37^{\circ} \mathrm{C}\right)$ cell culture medium. The cigarette was smoked at a rate of $50 \mathrm{~mL}$ over a period of $2 \mathrm{~s}$, followed by a $28 \mathrm{~s}$ pause.

USA). The concentration of the resulting undiluted extract was assigned a value of 1 . Subsequently, it was diluted with cell culture medium ( $\alpha$-MEM, Gibco, USA) and the serial diluted extracts were assigned relative values of $10 \%, 5 \%$, or $2 \%$ (10-, 20-, or 50-fold diluted extract), respectively [37]. $0 \%$ CSE was designated as cell culture medium ( $\alpha$-MEM, Gibco, USA). All the extracts contained $10 \%$ fetal bovine serum (FBS, Gibco, USA) and 1\% penicillin/streptomycin (Gibco, USA). The extracts were freshly prepared before experiments.

2.2. Sample Preparation. Pure titanium (99 wt.\% purity, China) samples were custom-made as disks $(\varnothing=5,30 \mathrm{~mm})$. The samples were ground using a series of silicon carbide (SiC) papers (600, 800, 1200, and 1500 grit). Subsequently, the samples were cleaned in an ultrasonic bath and dried in the ambient atmosphere. Then, the samples were immersed in $0 \%, 2 \%, 5 \%$, and $10 \%$ CSE in a humidified atmosphere containing $5 \% \mathrm{CO}_{2}$ and $95 \%$ air at $37^{\circ} \mathrm{C}$. The samples immersed in $0 \%$ CSE were denoted as Ti-control and used as the control group, while those immersed in $2 \%, 5 \%$, and $10 \%$ CSE were denoted as Ti-CSE-2, Ti-CSE-5, and Ti-CSE10 , respectively, and used as experimental groups.

2.3. Surface Characterization. Titanium samples with a diameter of $0.5 \mathrm{~cm}$ were immersed in $0.1 \mathrm{~mL}$ CSE $(0 \%, 2 \%, 5 \%$, and $10 \%)$ at $37^{\circ} \mathrm{C}$ in a humidified atmosphere of $5 \% \mathrm{CO}_{2}$ and 95\% air. After $3 \mathrm{~d}$, the samples were rinsed by double-distilled water and then dried before being used. Field-emission scanning electron microscopy (SEM, LEO, Germany) was employed to characterize the surface morphology of the prepared samples. The X-ray photoelectron spectroscopy (XPS) data were obtained with a Thermo Scientific Escalab 250Xi spectrometer. The chemical states of the components were also detected. The spectra were calibrated with respect to the $\mathrm{C} 1 \mathrm{~s}$ signal at $284.8 \mathrm{eV}$ [39]. The roughness and three-dimensional views of the surfaces of $\mathrm{Ti}$-control, $\mathrm{Ti}$ CSE-2, Ti-CSE-5, and Ti-CSE-10 samples were evaluated by 
confocal three-dimensional surface topography instrument (UP series, RTEC, USA). The surface hydrophilicity of Ticontrol, Ti-CSE-2, Ti-CSE-5, and Ti-CSE-10 samples was measured by the contact angle of $2 \mu \mathrm{L} \mathrm{H}_{2} \mathrm{O}$ using a contact angle measurement system (Model SL200B, Solon, China). A total of 16 titanium samples $(\varnothing=5 \mathrm{~mm})$ were used for the surface morphology, which were equally distributed among 4 group. The number and grouping of samples used for roughness/three-dimensional view and hydrophilicity are the same as the surface morphology. Ti-control and Ti-CSE-10 were selected as representative samples for determining the surface elemental compositions, and 8 titanium samples $(\varnothing$ $=5 \mathrm{~mm}$ ) were used for it.

2.4. Cell Culture. MC3T3-E1 cell is a highly characterized murine preosteoblastic cell line established from mouse calvaria [40]. MC3T3-E1 cell used in this study was purchased from Shanghai Cell Bank of Chinese Academy of Sciences (Shanghai, China). The cells were cultured in $\alpha$-Minimum Essential Medium ( $\alpha$-MEM, Gibco, USA) supplemented with $10 \%$ fetal bovine serum (FBS, Gibco, USA) and $1 \%$ antibodies containing penicillin/streptomycin (Gibco, USA) at $37^{\circ} \mathrm{C}$ in a humidified atmosphere of $5 \% \mathrm{CO}_{2}$ and $95 \%$ air. The culture medium was changed once every $2 \mathrm{~d}$. When the cells reached $80 \%$ confluency, they were trypsinized and passaged at a ratio of $1: 4$.

2.5. Cell Adhesion and Spreading Assay. To observe the morphology of MC3T3-E1 cells in different groups, the cells were seeded onto titanium samples with $0.5 \mathrm{~cm}$ diameter in 96-well plates $\left(5 \times 10^{3}\right.$ cells/well). The wells were filled

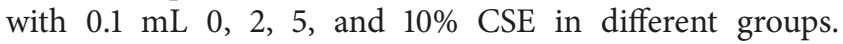
After $4 \mathrm{~h}$ and $8 \mathrm{~h}$ of incubation, the cells on the titanium samples were fixed with $4 \%$ paraformaldehyde (PAF) for 10 min at room temperature. After permeabilization with $0.5 \%$ Triton X-100, the cells in different groups were stained with $100 \mathrm{nM}$ rhodamine-phalloidin (Cytoskeleton, USA) at room temperature for $30 \mathrm{~min}$ in the dark. Then, cells were stained again with 100nM 4',6'-diamidino-2-phenylindole (DAPI) (Beyotime, China) for $30 \mathrm{~s}$. The images of adherent MC3T3E1 cells in four different groups were acquired at $200 \times$ magnification with a laser scanning confocal microscopy (LSM710, Zeiss, Germany). A total of 32 titanium samples $(\varnothing=5 \mathrm{~mm})$ were used in this assay and equally distributed among each group. Specifically, 4 groups at 2 time points were included in this assay, and the center field of each specimen was observed.

2.6. Cell Proliferation Assay. Cell proliferation ability was assessed by the Cell Counting Kit-8 (CCK-8, Biosharp, China). Briefly, MC3T3-E1 cells were seeded onto titanium samples with $0.5 \mathrm{~cm}$ diameter in 96-well plates $\left(2 \times 10^{3}\right.$ cells/well). The wells were filled with $0.1 \mathrm{~mL} 0,2,5$, and $10 \%$ CSE in different groups. After $1 \mathrm{~d}, 3 \mathrm{~d}$, and $6 \mathrm{~d}$ of incubation, each well was refilled with a fresh solution consisting of $10 \mu \mathrm{l}$ CCK-8 solution (Biosharp, China) and $0.1 \mathrm{~mL}$ culture medium, followed by $2 \mathrm{~h}$ incubation at $37^{\circ} \mathrm{C}$. Subsequently, the absorbance of the incubated solutions at $450 \mathrm{~nm}$ wavelength was measured by a microplate reader
(Spectramax190, MD, USA). A total of 48 titanium samples $(\varnothing=5 \mathrm{~mm})$ were used in this assay and equally distributed among each group. Specifically, 4 groups at 3 time points were included in this assay, and each group included four duplicate wells.

2.7. Alkaline Phosphatase (ALP) Activity Assay. For the ALP activity assay, MC3T3-E1 cells were seeded onto titanium samples with $3 \mathrm{~cm}$ diameter in 6 -well plates $\left(2 \times 10^{5}\right.$ cells/well $)$. The wells were filled with $2.5 \mathrm{~mL} 0,2,5$, and $10 \%$ CSE in different groups. After $7 \mathrm{~d}$ and $14 \mathrm{~d}$ of incubation, the cells on the samples were rinsed with $\mathrm{PBS}$ and then lysed $\left(4^{\circ} \mathrm{C}, 30\right.$ min) using radio-immunoprecipitation assay (RIPA) buffer (Leagene, China) in the presence of $1 \mathrm{mM}$ phenylmethylsulfonyl fluoride (PMSF, Leagene, China). The collected lysates were then centrifugated at $12000 \mathrm{rpm}$ at $4^{\circ} \mathrm{C}$ for $10 \mathrm{~min}$. The protein concentration of the liquid supernatants was determined using a BCA protein assay kit (Keygen Biotech, China). Then, the ALP activity was assessed using an AKP assay kit (Jiancheng Bioengineering Institute, China). A total of 32 titanium samples $(\varnothing=30 \mathrm{~mm}$ ) were used in this assay and equally distributed among each group. Specifically, 4 groups at 2 time points were included in this assay, and each group included four duplicate wells.

2.8. Western Blotting. Run-related transcription factor 2 (Runx2) and osterix (OSX) protein expressions in different groups were examined by Western blotting analyses. MC3T3E1 cells were seeded onto titanium samples with $3 \mathrm{~cm}$ diameter in 6-well plates $\left(2 \times 10^{5}\right.$ cells/well). The wells were filled

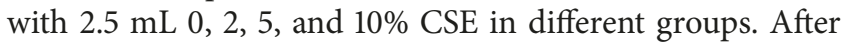
$7 \mathrm{~d}$ and $14 \mathrm{~d}$ of incubation, cells on the samples were gently rinsed with PBS before lysis in RIPA buffer in the presence of $1 \mathrm{mM}$ PMSF. The protein concentration of the liquid supernatants was determined using a BCA protein assay kit. Proteins were separated by SDS-PAGE and transferred to the polyvinylidene fluoride (PVDF) membranes (Millipore, USA). The membranes were then blocked with $5 \%$ skim milk for $1 \mathrm{~h}$ at room temperature. The blocked membranes were washed with TBS-T buffer and probed with different primary rabbit antibodies against Runx2 (12556, CST, USA), OSX (22552, Abcam, UK) and GAPDH (100118, GeneTex, USA) overnight at $4^{\circ} \mathrm{C}$. Subsequently, PVDF membranes were incubated with a secondary antibody (anti-rabbit, ZB2301, ZSGB-BIO, China) for 2 hours. The immunoreactive proteins were detected by using Immobilon Western Chemiluminescent HRP substrate (Millipore, USA). The relative expression levels of Runx2 and OSX proteins were normalized to GAPDH. A total of 24 titanium samples $(\varnothing=30 \mathrm{~mm})$ were used in this assay and equally distributed among each group. Specifically, 4 groups at 2 time points were included in this assay, which was performed in triplicate.

2.9. Statistical Analysis. Statistical analysis was performed using SPSS 22.0 (SPSS Inc., Chicago, IL, USA). The data were expressed as mean \pm standard deviation and analyzed by oneway analysis of variance (ANOVA). Statistical significance level was set at $P<0.05$. 

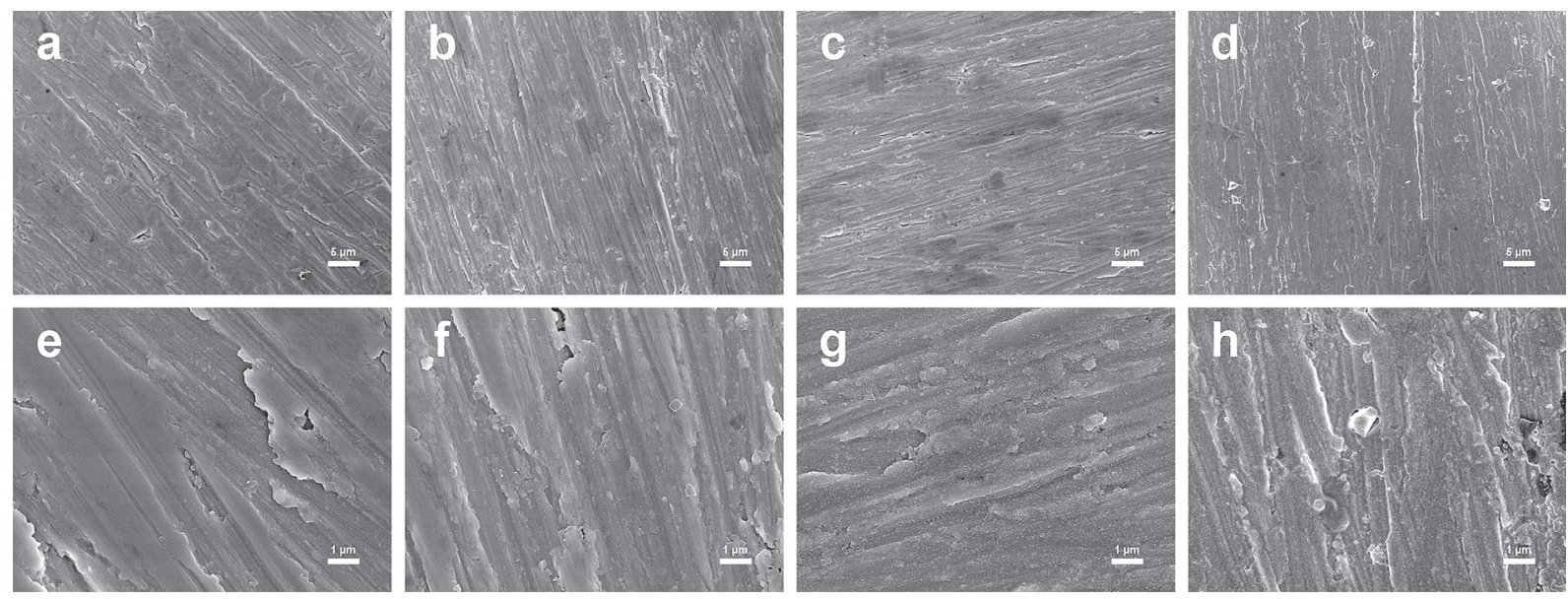

FIgURE 2: Scanning electron microscopy images of titanium samples under CSE exposure for $3 \mathrm{~d}$. Upper panel ((a) Ti-control; (b) Ti-CSE-2; (c) Ti-CSE-5; (d) Ti-CSE-10) images at 2000× magnification. Lower panel ((e) Ti-control; (f) Ti-CSE-2; (g) Ti-CSE-5; (h) Ti-CSE-10) images at $10000 \times$ magnification.

\section{Results and Discussion}

3.1. Surface Micromorphology and Elemental Composition. The result of SEM observation was shown in Figure 2. The surface morphologies of Ti-control, Ti-CSE-2, Ti-CSE5 , and Ti-CSE-10 samples did not show obvious differences under low magnification (Figures 2(a), 2(b), 2(c), and 2(d)). Different from the surfaces of Ti-control samples, particles could be observed on the surfaces of Ti-CSE-2, Ti-CSE-5, and Ti-CSE-10 samples under higher magnification (Figures 2(e), 2(f), 2(g), and 2(h)). From Ti-CSE-2 to Ti-CSE-10, an increasing number of particles appeared on the sample surfaces (Figures 2(f), 2(g), and 2(h)).

During the process of osseointegration, the formation and maintenance of new bone at the implant surfaces ensure the success of dental implants [41]. In this study, from the results of SEM observation, particles were found on the titanium surfaces under CSE exposure (Figure 2). Previous studies showed that CSE contained thousands of chemicals $[15,16]$. We speculated that these particles were derived from CSE. It could be conjectured that these substances adsorbed on the titanium surface, thereby influencing the surface micromorphology of the titanium surface.

The survey spectra by XPS acquired from the Ti-control and Ti-CSE-10 samples were displayed in Figure 3. Titanium $(\mathrm{Ti})$, oxygen $(\mathrm{O})$, carbon $(\mathrm{C})$, and nitrogen $(\mathrm{N})$ were present on both Ti-control and Ti-CSE-10 samples, while sodium $(\mathrm{Na})$ and chlorine $(\mathrm{Cl})$ only appeared on Ti-CSE10 samples (Figure 3(a)). In Figure 3(b), the $\mathrm{C}$ 1s highresolution spectra exhibited three peaks at about $284.68 \mathrm{eV}$, $286.08 \mathrm{eV}$, and $287.98 \mathrm{eV}$, respectively. High-energy peaks of $\mathrm{C}$ 1s were detected on Ti-control samples, which could probably be attributed to the immersion in the cell medium. Notably, high-energy peaks of C 1 s were detected on Ti-CSE10 samples. Therefore, some carbon-containing compounds from CSE adsorbed on Ti-CSE-10 samples. However, lowerenergy peaks of $\mathrm{Ti} 2 \mathrm{p}$ were detected at $464.38 \mathrm{eV}$ and $458.58 \mathrm{eV}$ on Ti-CSE-10 samples compared to the Ti-control samples (Figure 3(c)). Moreover, the O 1s peaks at $529.98 \mathrm{eV}$, indicating the existence of titanium dioxide $\left(\mathrm{TiO}_{2}\right)$, appeared on Ti-control samples rather than the Ti-CSE-10 samples (Figure 3(d)).

From the XPS data, sodium $(\mathrm{Na})$ and chlorine $(\mathrm{Cl})$ appeared on the Ti-CSE-10 samples (Figure 3(a)) and highenergy peaks of $C$ 1s were detected on the Ti-CSE-10 samples rather than Ti-control samples (Figure 3(b)), consistent with the result of SEM. Moreover, high-energy peaks of Ti $2 p$ were detected on the Ti-control samples (Figure 3(c)), and the $\mathrm{O}$ 1 s peaks at $529.98 \mathrm{eV}$ (Figure 3(d)), indicating the existence of titanium dioxide $\left(\mathrm{TiO}_{2}\right)$, appeared on the Ti-control samples rather than the Ti-CSE-10 samples. This comparison of results suggested that carbon-containing compounds adsorbed on the Ti-CSE-10 samples and the $\mathrm{TiO}_{2}$ layer of the Ti-CSE10 samples was covered after the immersion in the CSE. We speculated that the carbon-containing compounds adsorbing on the titanium surface in the smokers might affect the ossteointegration of implants. This result was consistent with a previous study by Att et al. [25], reporting progressive accumulation of hydrocarbons on titanium implants with passage of time. The Cls peak was considerably higher on the surface after 4 weeks of storage in dark ambient conditions than on the new surface. Normally, hydrocarbons contamination was present on titanium implants used for clinical and experimental use, which were routinely stored in ambient conditions $[42,43]$. Along this line, carboncontaining compounds from CSE could adsorb on titanium surface, as found in the present study.

3.2. Surface Roughness and the Hydrophilicity. The results of surface roughness assay were shown in Table 1. From the results, Ti-control, Ti-CSE-2, Ti-CSE-5, and Ti-CSE10 samples revealed similar surface roughness values $\left(R_{a}\right)$. Besides, the three-dimensional views of Ti-control, Ti-CSE-2, Ti-CSE-5, and Ti-CSE-10 samples did not show any obvious differences (Figure 4). As shown in Figure 5, the wettability assay did not reveal any significant differences of contact angles among Ti-control, Ti-CSE-2, Ti-CSE-5, and Ti-CSE10 samples. These results showed that CSE exposure did not 

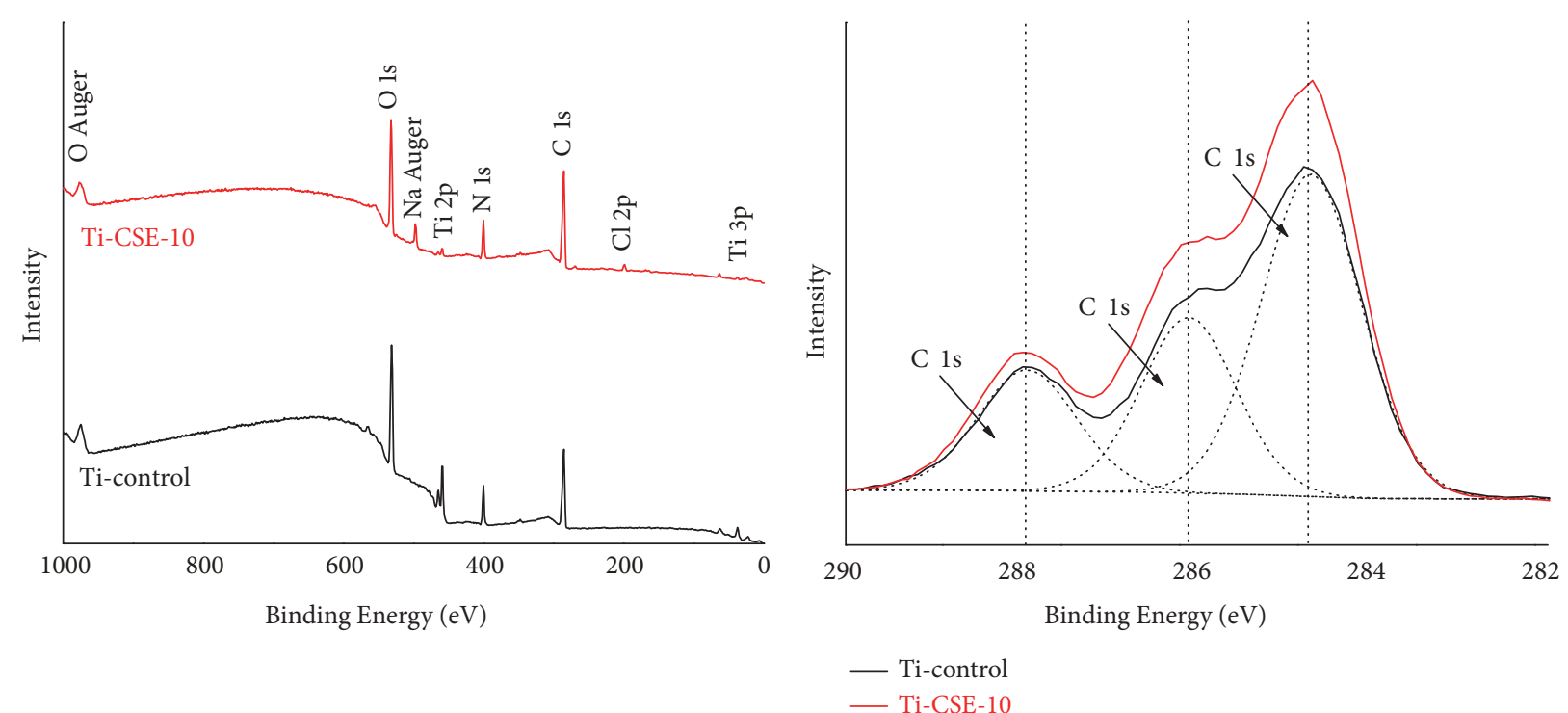

(a)

(b)

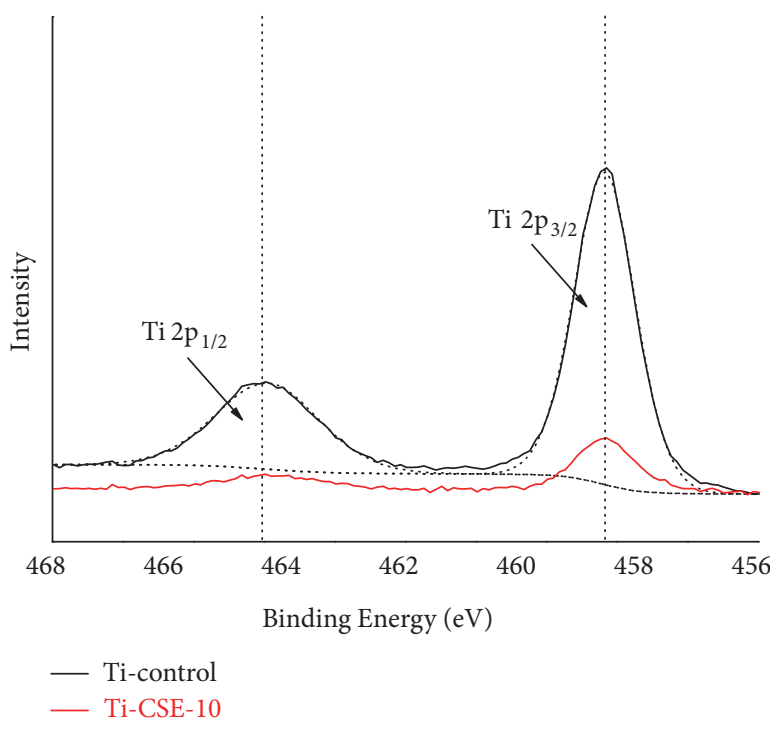

(c)

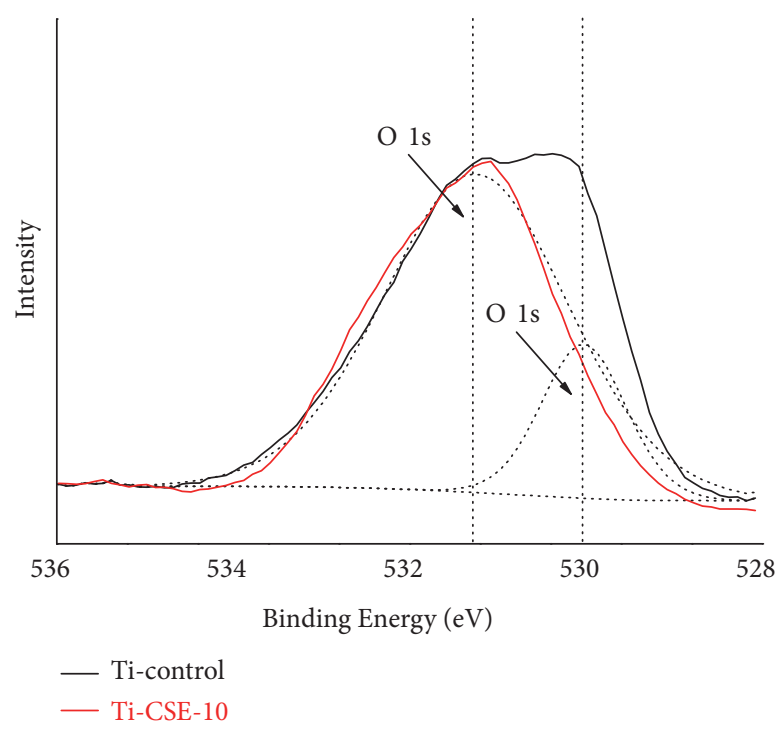

(d)

FIGURE 3: XPS spectra of titanium samples ((a) survey spectra of the samples; (b) high-resolution spectra of C $1 \mathrm{~s}$ on the samples; (c) highresolution spectra of Ti $2 \mathrm{p}$ on the samples; (d) high-resolution spectra of $\mathrm{O}$ 1s on the samples).

influence the roughness or the hydrophilicity of the titanium surfaces.

Thus, the physical properties of titanium samples under CSE exposure revealed that CSE could alter the micromorphology and elemental composition of titanium surface, excluding surface roughness and hydrophilicity. Furthermore, a study by Aita et al. [44] explored inverse correlation between carbon element on titanium and its osteoblast attractiveness. It suggested that the rate of osteoblast attachment increased exponentially with the progressive decrease of carbon. As reported by Att et al. [25], the amount of osteogenic cells adhering to the titanium implant surface
TABLE 1: $R_{a}$ values of surface roughness of four different groups $(n=4)$.

\begin{tabular}{lc}
\hline Group & $\mathrm{R}_{\mathrm{a}}(\mu \mathrm{M})$ \\
\hline Ti-control & $0.205 \pm 0.016$ \\
Ti-CSE-2 & $0.186 \pm 0.011$ \\
Ti-CSE-5 & $0.192 \pm 0.008$ \\
Ti-CSE-10 & $0.198 \pm 0.012$ \\
\hline
\end{tabular}

decreased with the increase of hydrocarbons on the titanium surface. 


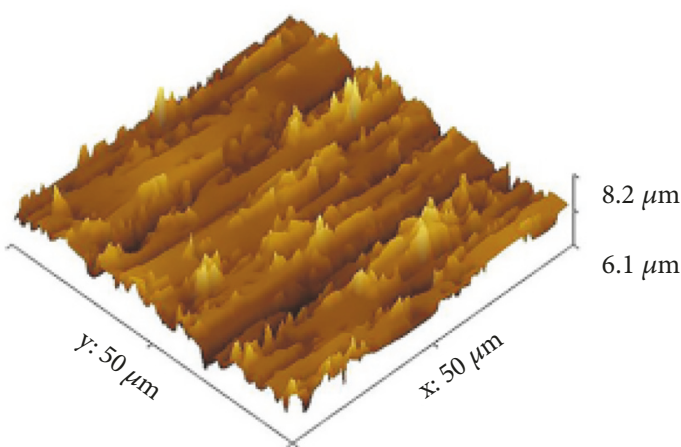

(a)

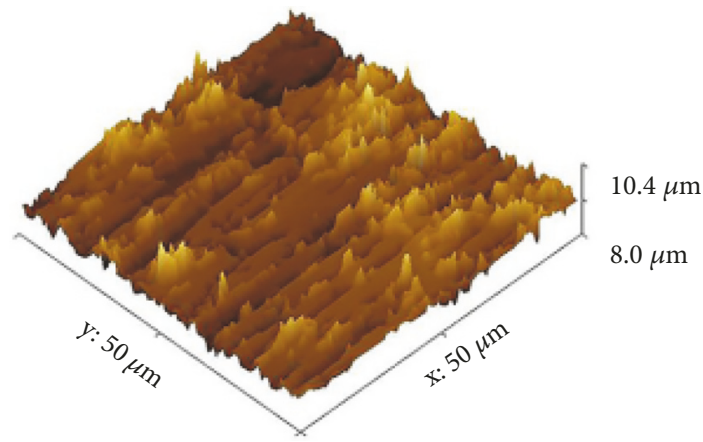

(c)

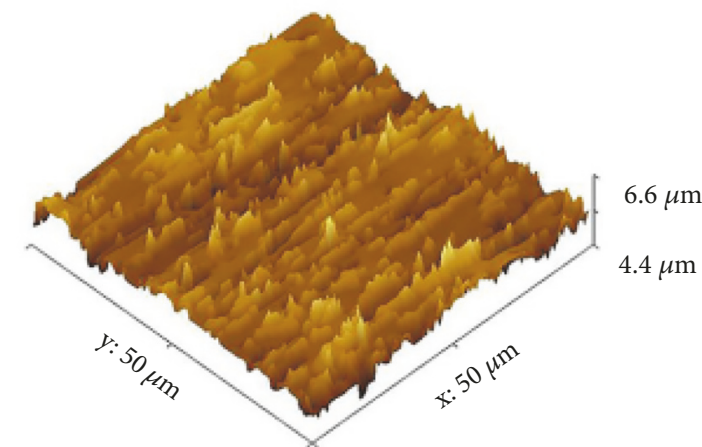

(b)

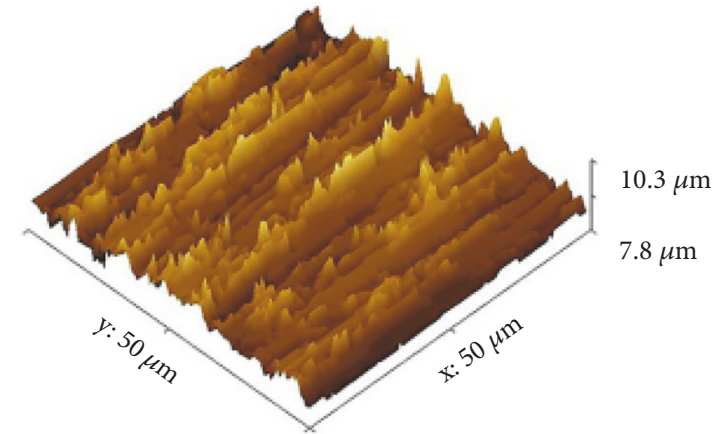

(d)

FIgure 4: Three-dimensional morphology of Ti-control (a), Ti-CSE-2 (b), Ti-CSE-5 (c), and Ti-CSE-10 (d) samples.

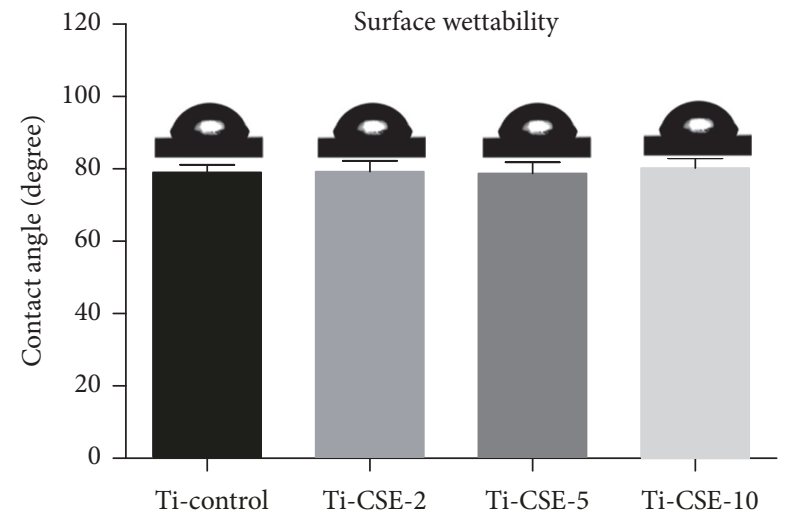

FIgURE 5: The contact angles of Ti-control, Ti-CSE-2, Ti-CSE-5, and Ti-CSE-10 samples.

3.3. Adhesion and Proliferation Ability of Osteoblasts under CSE Exposure. The adhesion behavior of MC3T3-E1 cells was observed under laser scanning confocal microscopy (Figure 6). After incubation for $4 \mathrm{~h}$ and $8 \mathrm{~h}$, the differences in the cell morphology were observed among different groups. With the increase of CSE concentration, the cells extended fewer pseudopodia and spread less. The cells in Ti-CSE-10 group demonstrated the worst cell-adhesion ability, followed by the Ti-CSE-5 and then the Ti-CSE- 2 groups. On the contrary, the cells in Ti-control group exibihited relatively normal morphology.
The cell proliferation ability was measured by CCK-8 assay (Figure 7). MC3T3-E1 cells steadily proliferated in all groups during culture period, except the Ti-CSE-10 groups. After 3 and $6 \mathrm{~d}$ of incubation, in Ti-control group, the cells proliferated and survived significantly more than those in Ti-CSE-2, Ti-CSE-5, and Ti-CSE-10 groups. CSE exposure downregulated the proliferation of MC3T3-E1 cells in a dosedependent fashion.

The results of cell spreading and proliferation showed that the CSE exposure influenced the biological behavior of the osteoblasts on the titanium samples. In addition, a high concentration of CSE exhibited cellular cytotoxicity. This evidence revealed that the CSE exposure could affect the adhesion and proliferation of the osteoblasts on the titanium surface. This was in consistency with a recent study by Cyprus et al. [45] who employed CSE exposure as a stimulating factor on macrophages and MSCs and found that CSE exposure attenuated cell viability of macrophage and MSC in a dose-dependent manner. It demonstrated that CSE exposure decreased osteogenic differentiation and anti-inflammatory interleukin production while increasing proinflammatory interleukin production in macrophages and MSCs on titanium surfaces. Reportedly, the adhesion and subsequent proliferation of osteoblastic cells on the implant surface are responsible for implant osseointegration [46]. CSE exposure could inhibit chemotaxis mediated by human bone marrow osteoprogenitor cells and osteoblastlike cells [47]. Acetaldehyde, one of the components of CSE, also inhibited the cell proliferation in human osteoblastic 

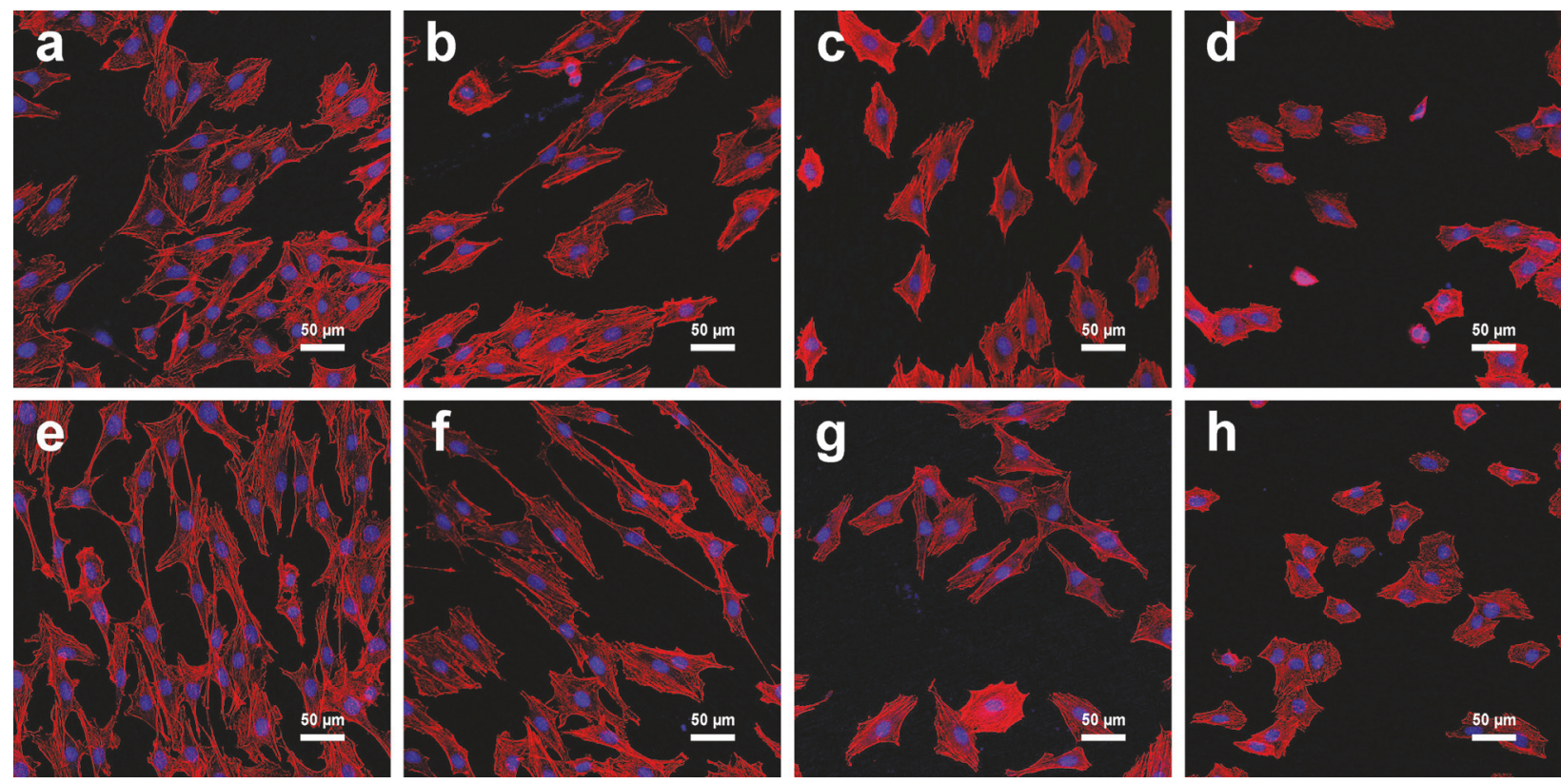

FIGURE 6: Fluorescence images of MC3T3-E1 cells spreading in four groups after $4 \mathrm{~h}$ and $8 \mathrm{~h}$ of incubation (magnification 200×). Upper panel ((a) Ti-control; (b) Ti-CSE-2; (c) Ti-CSE-5; (d) Ti-CSE-10) displays cell spreading after $4 \mathrm{~h}$ of incubation. Lower panel ((e) Ti-control; (f) Ti-CSE-2; (g) Ti-CSE-5; (h) Ti-CSE-10) displays cell spreading after $8 \mathrm{~h}$ of incubation.

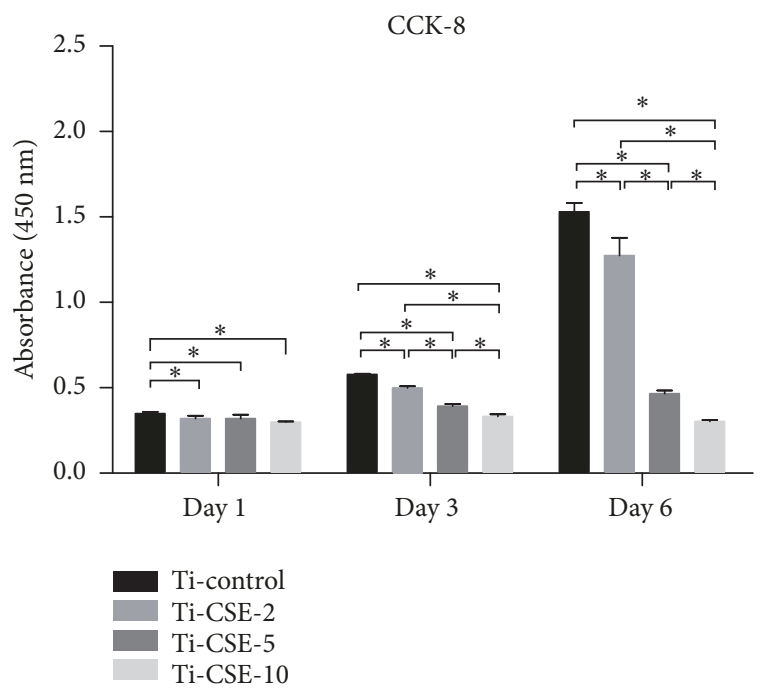

FIGURE 7: After incubation for 1,3, and $6 \mathrm{~d}$, cell proliferation ability of MC3T3-E1 cells adhering to the titanium samples in Ti-control, Ti-CSE-2, Ti-CSE-5, and Ti-CSE-10 groups was analyzed by the CCK-8 assay. $*$ indicated significant differences between different samples $(P<0.05)$.

cells [46]. Thus, the conclusions of these previous studies confirmed the current results in the present study.

\subsection{Osteogenic Differentiation Behavior of Osteoblasts under} CSE Exposure. The results of ALP activity assay were shown in Figure 8. After incubation for $7 \mathrm{~d}$, the MC3T3-El cells in Ticontrol group showed higher ALP activity than those in the Ti-CSE-2, Ti-CSE-5, and Ti-CSE-10 groups. After incubation for $14 \mathrm{~d}$, the ALP activity of MC3T3-E1 cells in Ti-control group showed a clear dominance compared to those in the Ti-CSE-2, Ti-CSE-5, and Ti-CSE-10 groups. What is more, the ALP activity of osteoblasts in the Ti-control group had a significant increase at the end of culture. Interestingly, the ALP activity of osteoblasts in the Ti-CSE-2, Ti-CSE-5, and TiCSE-10 groups decreased with the passage of culture time.

The osteogenic lineage protein expression levels in the four groups were examined by Western blotting analysis. As shown in Figure 9, at culture days 7 and 14, the expression level of Runx2 gradually declined with the increase of CSE concentration. MC3T3-E1 cells in three experimental groups exhibited lower expression levels of Runx2 than those in Ti-control group. Similar to Runx2, the expression level of OSX steadily declined with the increase of CSE concentration at culture days 7 and 14. The Ti-CSE-10 group exhibited lowest expression levels of OSX. Hence, the CSE exposure could negatively affect the cell differentiation activities of the osteoblasts.

Osseointegration and osteogenic differentiation are critical for clinical outcomes involving implants in the orthopedics and dentistry [48-50]. ALP is considered as an early marker for osteogenic differentiation [51]. In this study, the ALP activity of osteoblasts on the titanium surface significantly decreased under the CSE exposure. This result was in agreement with the observations of Cyprus et al. [45], reporting that CSE exposure downregulated alkaline phosphatase activity of MSCs. Runx2 and Osterix (OSX) were commonly selected to analyze the osteogenic differentiation abilities. Runx2, a vital transcription factor, was expressed during the early stage of osteogenic differentiation and directs mesenchymal progenitor cells to preosteoblasts. OSX is required for the differentiation of preosteoblasts into 


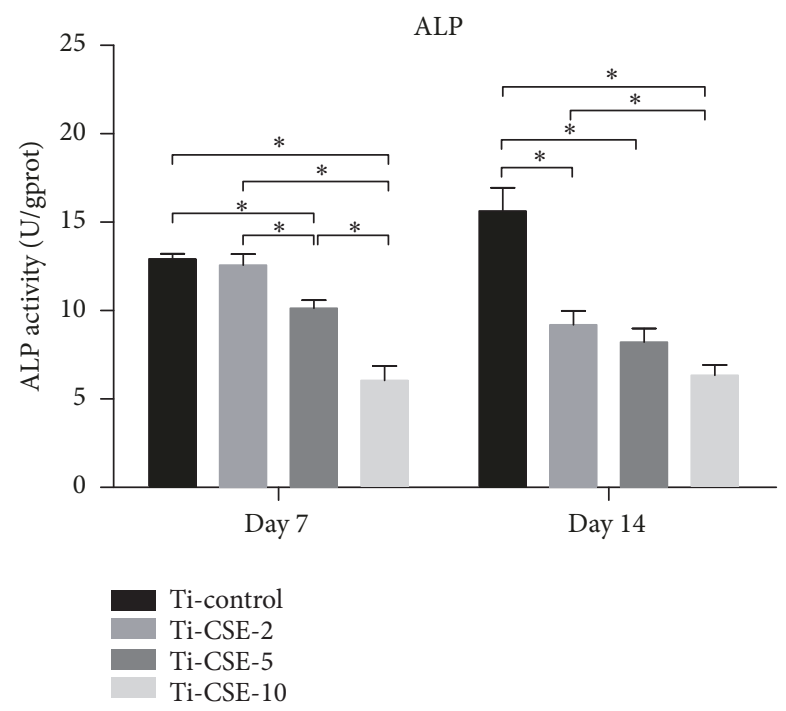

FIGURE 8: The alkaline phosphatase (ALP) activity of MC3T3-E1 cells in Ti-control, Ti-CSE-2, Ti-CSE-5, and Ti-CSE-10 groups after incubation for $7 \mathrm{~d}$ and $14 \mathrm{~d}$. $*$ indicated significant differences between different samples $(P<0.05)$.

mature osteoblasts [52]. In this study, the expression level of Runx 2 and OSX steadily declined with the increase of CSE concentration. Previous studies found that CSE exposure exerts a negative impact on the osteogenic differentiation $[53,54]$. The conclusions of these studies were consistent with our results. Therefore, it can be speculated that these CSEoriginated carbon-containing compounds, which adsorbed on the titanium surface, affected osteogenic differentiation ability of osteoblasts.

Several in vitro studies have demonstrated that specific components of cigarette smoke, like nicotine, acrolein, and acetaldehyde, inhibited functions of human bone marrowderived cells or osteoblastic cells cultured on titanium surfaces $[46,55]$. However, those studies focused on single or several compounds of cigarette smoke. Another method for studying tobacco smoke in vitro was to prepare the cigarette smoke extracts. Since the usage of CSE is limited by the quality of the smoke extract preparation, we elected to use a smoke extract preparation method provided by Bernhard et al. [38], which guaranteed a similarity to the in vivo situation. According to the method, we controlled the puffing rhythm to mimic the average smoker, since the actual tobacco smoke toxicity was affected by the intensity, speed, and periodicity of the airflow through the cigarette [38]. With the help of this in vitro model, effect of cigarette smoke on implants can be explored at the biomolecular level. It should be mentioned that differences exist between the in vitro conditions and the actual in vivo exposure at the bone-implant interface. Therefore, further in vivo experiments with animals are required.

It was well understood that the predictable success of a dental implant was dependent on the level of crestal bone preservation around implant. A number of clinical researches reported that bone loss around implant was higher for smokers compared with nonsmokers. For instance,
Moraschini et al. observed a statistically significant difference in marginal bone loss between the smoking group and the nonsmoking group, in favour of the nonsmoking group [56]. Vervaeke et al. reported that the estimated bone loss around implant was $1.2 \mathrm{~mm}$ higher for smokers compared with nonsmokers [57]. Furthermore, an in vivo study reported that cigarette smoke inhalation could result in a decreased bone healing around titanium implants [58]. While those published works have demonstrated that smoking is closely related to peri-implant bone loss, the exact mechanism did not reach a consensus. Through in vitro and in vivo studies using the method of CSE exposure, which was similar to our study, Cyprus et al. [45] attributed the deleterious effect of smoking on the osseointegration to the inflammatory response. According to this study, in parallel with our research, CSE exposure model may be useful for predicting how cigarette smoke may adversely affect the outcome of implants.

The present study explored the negative influence of CSE exposure on the cell-material interactions. It investigated the changes in the characteristics of titanium surface and biological responses of MC3T3-E1 cells to titanium surface under CSE exposure. The results uncovered that the CSEoriginated carbon-containing compounds could adsorb on the titanium surface in the osteoblast-titanium interactions. We hope that the results of this study could be valuable for elucidating the exact effects of cigarette smoking on the early osseointegration of the titanium implant. In addition, the in vivo impacts of CSE exposure on the osteoblast-titanium interactions, as well as its underlying molecular mechanism, require further investigations.

\section{Conclusions}

In this study, we investigated effect of CSE exposure on the titanium surface characteristics and the osteoblasttitanium interactions. The surface micromorphology and elemental composition of titanium surface changed under CSE exposure. The analysis of surface characteristics showed that some carbon-containing compounds adsorbed on the titanium surface. Additionally, the results of in vitro study showed that CSE exposure downregulated the cell spreading, proliferation, and osteogenic differentiation of MC3T3-E1 cells on the titanium surface. These findings demonstrated that CSE exposure altered the micromorphology and elemental composition of titanium surface due to the carboncontaining compounds adsorption, which, in turn, influenced the osteoblast-titanium interactions. Therefore, we suggested that the carbon-containing compounds adsorption might be an important cause of smoking-mediated inhibition of the osseointegration. It is earnestly hoped that the present study could provide valuable information for exploring the initiating causes of smoking-mediated inhibition of the implant osseointegration.

\section{Data Availability}

The data used to support the findings of this study are available from the corresponding author upon request. 

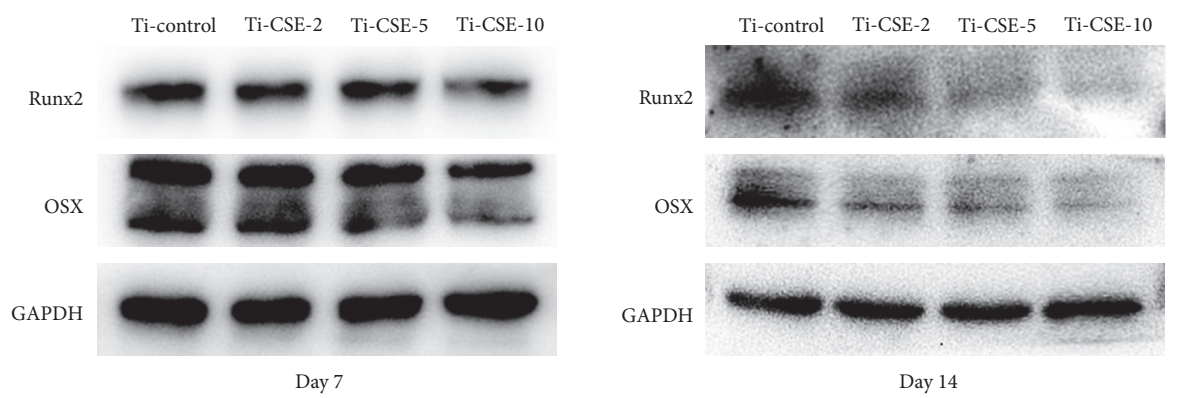

FIGURE 9: Osteogenic-related protein expression levels of Runx2 and OSX of MC3T3-E1 cells in Ti-control, Ti-CSE-2, Ti-CSE-5, and Ti-CSE10 groups were detected by Western blotting after $7 \mathrm{~d}$ and $14 \mathrm{~d}$ of incubation.

\section{Conflicts of Interest}

All authors declare that they have no conflicts of interest with the contents of this article.

\section{Authors' Contributions}

Jie Yang and Shui-yi Shao contributed equally to this work.

\section{Acknowledgments}

This study was supported by the National Natural Science Foundation of China (Projects nos. 81472928 and 81870799), the Medical Science Foundation of Jiangsu Provincial Health Department (Project no. H201641), the Jiangsu Provincial Medical Youth Talent (Project no. QNRC2016850), the Southeast University-Nanjing Medical University Cooperative Research Project (Project no. 2242017K3DN14), the Nanjing Medical University-SUYAN Group Intelligent Innovation Research and Development Project (Project no. NMUSY201806), and the Science and Technology Development Foundation of Nanjing Medical University (Project no. 2017NJMU101).

\section{References}

[1] A. Peacock, J. Leung, S. Larney et al., "Global statistics on alcohol, tobacco and illicit drug use: 2017 status report," Addiction, vol. 113, no. 10, pp. 1905-1926, 2018.

[2] E. Aluckal and S. Lakshmanan, "The feasibility of smoker's surcharge policy in tobacco control," Journal of Cancer Research and Therapeutics, vol. 13, no. 6, pp. 1075-1076, 2017.

[3] C. M. Willinger, J. Rong, K. Tanriverdi et al., "MicroRNA signature of cigarette smoking and evidence for a putative causal role of MicroRNAs in Smoking-related inflammation and target organ damage," Circulation: Cardiovascular Genetics, vol. 10, no. 5, Article ID e001678, 2017.

[4] Y.-J. Zhang, L. Zhang, X.-L. Huang, Y. Duan, L.-J. Yang, and J. Wang, "Association between cigarette smoking and impaired clinical symptoms in systemic sclerosis: A review," Cellular Immunology, vol. 318, pp. 1-7, 2017.

[5] R. A. Pauwels, A. S. Buist, P. M. A. Calverley, C. R. Jenkins, S. S. Hurd, and GOLD Scientific Committee, "Global strategy for the diagnosis, management and prevention of chronic obstructive pulmonary disease. NHBLI/WHO Global initiative for chronic obstructive lung disease (GOLD) workshop summary," American Journal of Respiratory and Critical Care Medicine, vol. 163, no. 5, pp. 1256-1276, 2001.

[6] J. Reibel, "Tobacco and oral diseases: Update on the evidence, with recommendations," Medical Principles and Practice, vol. 12, no. 1, pp. 22-32, 2003.

[7] D. Schwartz-Arad, N. Samet, N. Samet, and A. Mamlider, "Smoking and complications of endosseous dental implants," Journal of Periodontology, vol. 73, no. 2, pp. 153-157, 2002.

[8] L. J. A. Heitz-Mayfield and G. Huynh-Ba, "History of treated periodontitis and smoking as risks for implant therapy," The International Journal of Oral \& Maxillofacial Implants, vol. 24, supplement, pp. 39-68, 2009.

[9] B. R. Chrcanovic, T. Albrektsson, and A. Wennerberg, "Smoking and dental implants: a systematic review and meta-analysis," Journal of Dentistry, vol. 43, no. 5, pp. 487-498, 2015.

[10] R. Cavalcanti, F. Oreglia, M. F. Manfredonia, R. Gianserra, and M. Esposito, "The influence of smoking on the survival of dental implants: a 5-year pragmatic multicentre retrospective cohort study of 1727 patients," European Journal of Oral Implantology, vol. 4, no. 1, pp. 39-45, 2011.

[11] J. A. Shibli, A. Piattelli, G. Iezzi et al., "Effect of smoking on early bone healing around oxidized surfaces: a prospective, controlled study in human jaws," Journal of Periodontology, vol. 81, no. 4, pp. 575-583, 2010.

[12] J. D. Bezerra Ferreira, J. A. Rodrigues, A. Piattelli, G. Iezzi, S. A. Gehrke, and J. A. Shibli, “The effect of cigarette smoking on early osseointegration of dental implants: a prospective controlled study," Clinical Oral Implants Research, vol. 27, no. 9, pp. 11231128, 2016.

[13] H. De Bruyn and B. Collaert, "The effect of smoking on early implant failure," Clinical Oral Implants Research, vol. 5, no. 4, pp. 260-264, 1994.

[14] B. R. Chrcanovic, J. Kisch, T. Albrektsson, and A. Wennerberg, "Factors influencing early dental implant failures," Journal of Dental Research, vol. 95, no. 9, pp. 995-1002, 2016.

[15] T. Adam, R. R. Baker, and R. Zimmermann, "Investigation, by single photon ionisation (SPI)-time-of-flight mass spectrometry (TOFMS), of the effect of different cigarette-lighting devices on the chemical composition of the first cigarette puff," Analytical and Bioanalytical Chemistry, vol. 387, no. 2, pp. 575584, 2007.

[16] S. S. Hecht, "Cigarette smoking: Cancer risks, carcinogens, and mechanisms," Langenbeck's Archives of Surgery, vol. 391, no. 6, pp. 603-613, 2006.

[17] P. Altuna, E. Lucas-Taulé, J. Gargallo-Albiol, O. FiguerasÁlvarez, F. Hernández-Alfaro, and J. Nart, "Clinical evidence on 
titanium-zirconium dental implants: A systematic review and meta-analysis," International Journal of Oral and Maxillofacial Surgery, vol. 45, no. 7, pp. 842-850, 2016.

[18] M. Xuereb, J. Camilleri, and N. J. Attard, "Systematic review of current dental implant coating materials and novel coating techniques," International Journal of Prosthodontics, vol. 28, no. 1, pp. 51-59, 2015.

[19] M. Chiapasco, M. Zaniboni, and M. Boisco, "Augmentation procedures for the rehabilitation of deficient edentulous ridges with oral implants," Clinical Oral Implants Research, vol. 17, supplement 2, pp. 136-159, 2006.

[20] B. B. Benatti, J. B. César-Neto, P. F. Gonçalves, E. A. Sallum, and F. H. Nociti Jr., "Smoking affects the self-healing capacity of periodontal tissues. A histological study in the rat," European Journal of Oral Sciences, vol. 113, no. 5, pp. 400-403, 2005.

[21] M. Cheng, Y. Qiao, Q. Wang et al., "Calcium plasma implanted titanium surface with hierarchical microstructure for improving the bone formation," ACS Applied Materials \& Interfaces, vol. 7, no. 23, pp. 13053-13061, 2015.

[22] R. Agarwal and A. J. García, "Biomaterial strategies for engineering implants for enhanced osseointegration and bone repair," Advanced Drug Delivery Reviews, vol. 94, pp. 53-62, 2015.

[23] P. K. Moy, D. Medina, V. Shetty, and T. L. Aghaloo, "Dental implant failure rates and associated risk factors," The International Journal of Oral \& Maxillofacial Implants, vol. 20, no. 4, pp. 569-577, 2005.

[24] W. Att and T. Ogawa, "Biological aging of implant surfaces and their restoration with ultraviolet light treatment: A novel understanding of osseointegration," The International Journal of Oral \& Maxillofacial Implants, vol. 27, no. 4, pp. 753-761, 2012.

[25] W. Att, N. Hori, M. Takeuchi et al., "Time-dependent degradation of titanium osteoconductivity: An implication of biological aging of implant materials," Biomaterials, vol. 30, no. 29, pp. 5352-5363, 2009.

[26] H. Tal, "Spontaneous early exposure of submerged implants: I. Classification and clinical observations," Journal of Periodontology, vol. 70, no. 2, pp. 213-219, 1999.

[27] M. C. Çehreli, A. M. Kökat, S. Uysal, and K. Akca, "Spontaneous early exposure and marginal bone loss around conventionally and early-placed submerged implants: A double-blind study," Clinical Oral Implants Research, vol. 21, no. 12, pp. 1327-1333, 2010.

[28] S.-M. Jeong, B.-H. Choi, J. Li, H.-S. Kim, C.-Y. Ko, and S.-H. Lee, "Influence of abutment connections and plaque control on the initial healing of prematurely exposed implants: An experimental study in dogs," Journal of Periodontology, vol. 79, no. 6, pp. 1070-1074, 2008.

[29] T.-H. Kim, D.-W. Lee, C.-K. Kim, K.-H. Park, and I.-S. Moon, "Influence of early cover screw exposure on crestal bone loss around implants: intraindividual comparison of bone level at exposed and non-exposed implants," Journal of Periodontology, vol. 80, no. 6, pp. 933-939, 2009.

[30] W. Zhang, M. Fang, F. Song, and L. J. Windsor, "Effects of cigarette smoke condensate and nicotine on human gingival fibroblast-mediated collagen degradation," Journal of Periodontology, vol. 82, no. 7, pp. 1071-1079, 2011.

[31] H. Tal, Z. Artzi, O. Moses, C. E. Nemcovsky, and A. Kozlovsky, "Spontaneous early exposure of submerged endosseous implants resulting in crestal bone loss: a clinical evaluation between stage I and stage II surgery," The International Journal of Oral \& Maxillofacial Implants, vol. 16, no. 4, pp. 514-521, 2001.

[32] S. P. Nana-Sinkam, D. L. Jong, S. Sotto-Santiago et al., "Prostacyclin prevents pulmonary endothelial cell apoptosis induced by cigarette smoke," American Journal of Respiratory and Critical Care Medicine, vol. 175, no. 7, pp. 676-685, 2007.

[33] G. Volpi, F. Facchinetti, N. Moretto, M. Civelli, and R. Patacchini, "Cigarette smoke and $\alpha, \beta$-unsaturated aldehydes elicit VEGF release through the p38 MAPK pathway in human airway smooth muscle cells and lung fibroblasts," British Journal of Pharmacology, vol. 163, no. 3, pp. 649-661, 2011.

[34] N. Moretto, F. Facchinetti, T. Southworth, M. Civelli, D. Singh, and R. Patacchini, " $\alpha, \beta$-Unsaturated aldehydes contained in cigarette smoke elicit IL-8 release in pulmonary cells through mitogen-activated protein kinases," American Journal of Physiology-Lung Cellular and Molecular Physiology, vol. 296, no. 5, pp. L839-L848, 2009.

[35] D. M. Comer, J. S. Elborn, and M. Ennis, "Inflammatory and cytotoxic effects of acrolein, nicotine, acetylaldehyde and cigarette smoke extract on human nasal epithelial cells," $B M C$ Pulmonary Medicine, vol. 14, no. 1, article no 32, 2014.

[36] N. T. Sanders, D. J. Dutson, J. W. Durrant et al., "Cigarette smoke extract (CSE) induces RAGE-mediated inflammation in the Ca9-22 gingival carcinoma epithelial cell line," Archives of Oral Biolog, vol. 80, pp. 95-100, 2017.

[37] Y. Ouyang, N. Virasch, P. Hao et al., "Suppression of human IL-1beta, IL-2, IFN-gamma, and TNF-alpha production by cigarette smoke extracts," Journal of Allergy Clinical Immunology, vol. 106, no. 2, pp. 280-287, 2000.

[38] D. Bernhard, C. W. Huck, T. Jakschitz et al., "Development and evaluation of an in vitro model for the analysis of cigarette smoke effects on cultured cells and tissues," Journal of Pharmacological and Toxicological Methods, vol. 50, no. 1, pp. 45-51, 2004.

[39] P.-P. Ming, S.-Y. Shao, J. Qiu et al., "Superiority of calciumcontaining nanowires modified titanium surface compared with SLA titanium surface in biological behavior of osteoblasts: A pilot study," Applied Surface Science, vol. 416, pp. 790-797, 2017.

[40] H. Ochiai, S. Okada, A. Saito et al., "Inhibition of IGF-1 expression by prolonged TGF- $\beta 1$ administration suppresses osteoblast differentiation," The Journal of Biological Chemistry, vol. 287, no. 27, pp. 22654-22661, 2012.

[41] T. Masuda, P. K. Yliheikkilä, D. A. Felton, and L. F. Cooper, "Generalizations regarding the process and phenomenon of osseointegration. Part I. In vivo studies," The International Journal of Oral \& Maxillofacial Implants, vol. 13, no. 1, pp. 1729, 1998.

[42] A. P. Serro and B. Saramago, "Influence of sterilization on the mineralization of titanium implants induced by incubation in various biological model fluids," Biomaterials, vol. 24, no. 26, pp. 4749-4760, 2003.

[43] D. Buser, N. Broggini, M. Wieland et al., "Enhanced bone apposition to a chemically modified SLA titanium surface," Journal of Dental Research, vol. 83, no. 7, pp. 529-533, 2004.

[44] H. Aita, N. Hori, M. Takeuchi et al., "The effect of ultraviolet functionalization of titanium on integration with bone," Biomaterials, vol. 30, no. 6, pp. 1015-1025, 2009.

[45] G. N. Cyprus, J. W. Overlin, K. M. Hotchkiss, S. Kandalam, and R. Olivares-Navarrete, "Cigarette smoke increases proinflammatory markers and inhibits osteogenic differentiation in 
experimental exposure model," Acta Biomaterialia, vol. 76, pp. 308-318, 2018.

[46] M. L. Pereira, J. C. Carvalho, F. Peres, and M. H. Fernandes, "Simultaneous effects of nicotine, acrolein, and acetaldehyde on osteogenic-induced bone marrow cells cultured on plasmasprayed titanium implants," The International Journal of Oral \& Maxillofacial Implants, vol. 25, no. 1, pp. 112-122, 2010.

[47] X. Liu, T. Kohyama, T. Kobayashi et al., "Cigarette smoke extract inhibits chemotaxis and collagen gel contraction mediated by human bone marrow osteoprogenitor cells and osteoblast-like cells," Osteoporosis International, vol. 14, no. 3, pp. 235-242, 2003.

[48] R. Smeets, B. Stadlinger, F. Schwarz et al., "Impact of dental implant surface modifications on osseointegration," BioMed Research International, vol. 2016, Article ID 6285620, 16 pages, 2016.

[49] V. Goriainov, R. Cook, J. M. Latham, D. G. Dunlop, and R. O. C. Oreffo, "Bone and metal: an orthopaedic perspective on osseointegration of metals," Acta Biomaterialia, vol. 10, no. 10, pp. 4043-4057, 2014.

[50] I. Wall, N. Donos, K. Carlqvist, F. Jones, and P. Brett, "Modified titanium surfaces promote accelerated osteogenic differentiation of mesenchymal stromal cells in vitro," Bone, vol. 45, no. 1, pp. 17-26, 2009.

[51] C. S. Park, T. H. Ha, M. Kim et al., "Fast and sensitive nearinfrared fluorescent probes for ALP detection and 3D printed calcium phosphate scaffold imaging in vivo," Biosensors \& Bioelectronics, vol. 105, pp. 151-158, 2018.

[52] J. Zhu, E. Shimizu, X. Zhang, N. C. Partridge, and L. Qin, "EGFR signaling suppresses osteoblast differentiation and inhibits expression of master osteoblastic transcription factors Runx2 and Osterix," Journal of Cellular Biochemistry, vol. 112, no. 7, pp. 1749-1760, 2011.

[53] X. D. Liu, Y. K. Zhu, T. Umino et al., "Cigarette smoke inhibits osteogenic differentiation and proliferation of human osteoprogenitor cells in monolayer and three-dimensional collagen gel culture," Journal of Laboratory and Clinical Medicine, vol. 137, no. 3, pp. 208-219, 2001.

[54] I. Sung, B. Park, Y. Hah et al., "FOXO1 is involved in the effects of cigarette smoke extract on osteoblastic differentiation of cultured human periosteum-derived cells," International Journal of Medical Sciences, vol. 12, no. 11, pp. 881-890, 2015.

[55] M. L. Pereira, J. C. Carvalho, F. Peres, M. Gutierres, and M. H. Fernandes, "Behaviour of human osteoblastic cells cultured on plasma-sprayed titanium implants in the presence of nicotine," Clinical Oral Implants Research, vol. 19, no. 6, pp. 582-589, 2008.

[56] V. Moraschini and E. D. P. Barboza, "Success of dental implants in smokers and non-smokers: a systematic review and meta-analysis," International Journal of Oral and Maxillofacial Surgery, vol. 45, no. 2, pp. 205-215, 2016.

[57] S. Vervaeke, B. Collaert, J. Cosyn, and H. De Bruyn, "A 9-year prospective case series using multivariate analyses toidentify predictors of early and late peri-implant bone loss," Clinical Implant Dentistry and Related Research, vol. 18, no. 1, pp. 30-39, 2016.

[58] J. B. César-Neto, P. M. Duarte, E. A. Sallum, D. Barbieri, H. Moreno Jr., and F. H. Nociti Jr., "A comparative study on the effect of nicotine administration and cigarette smoke inhalation on bone healing around titanium implants," Journal of Periodontology, vol. 74, no. 10, pp. 1454-1459, 2003. 


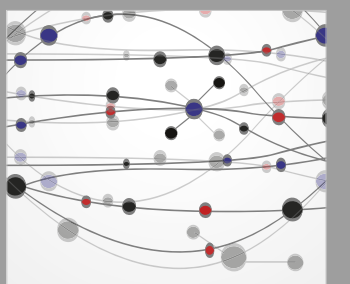

The Scientific World Journal
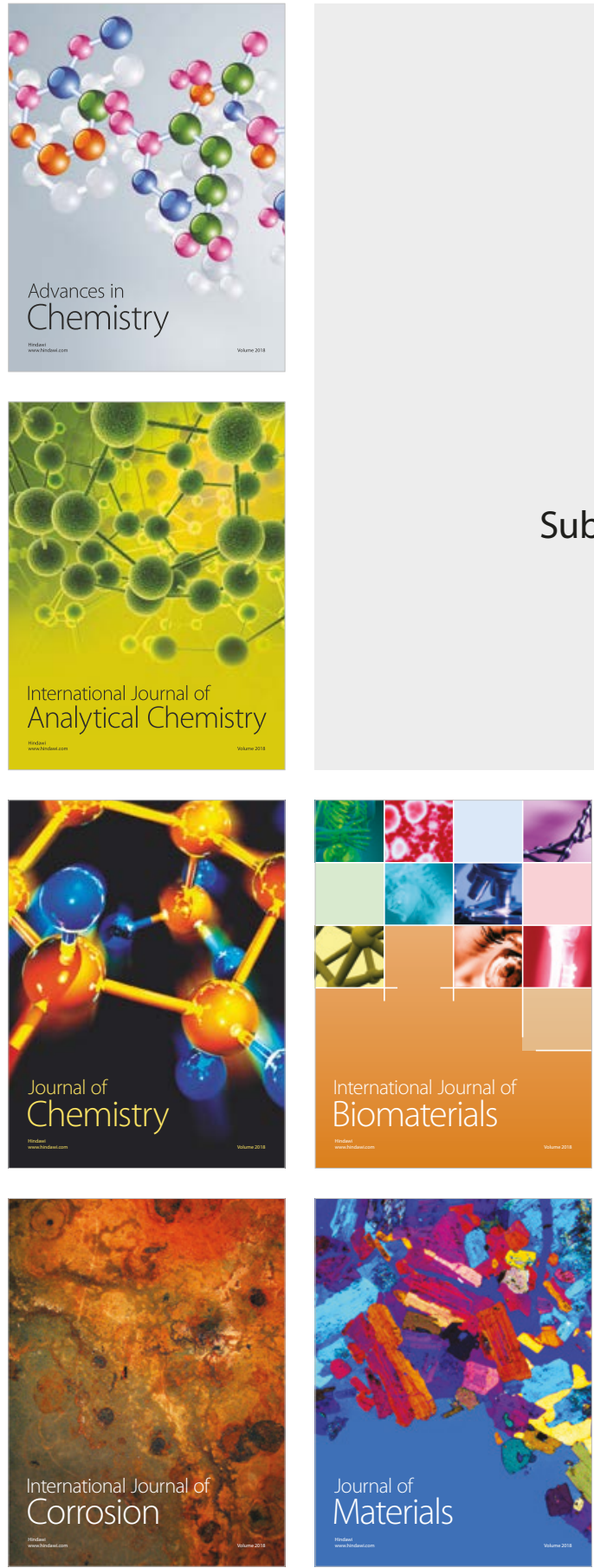

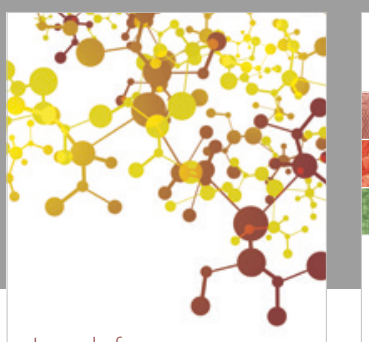

Journal of

Applied Chemistry
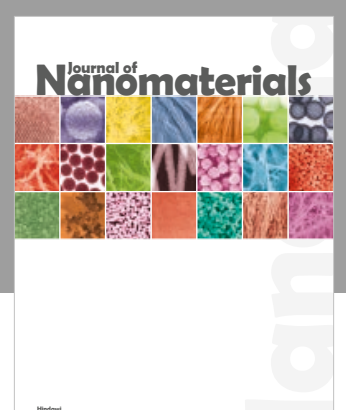

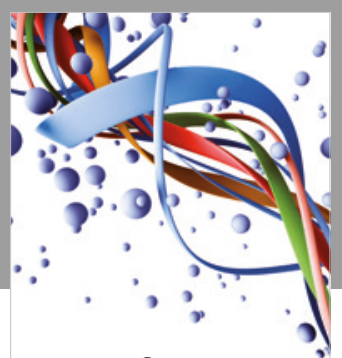

Scientifica

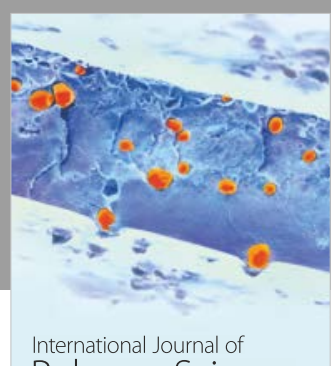

Polymer Science

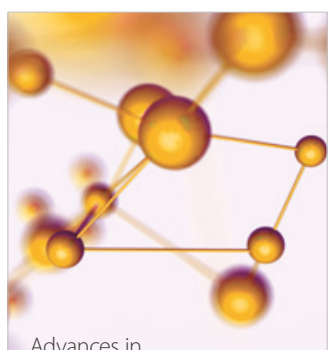

Physical Chemistry
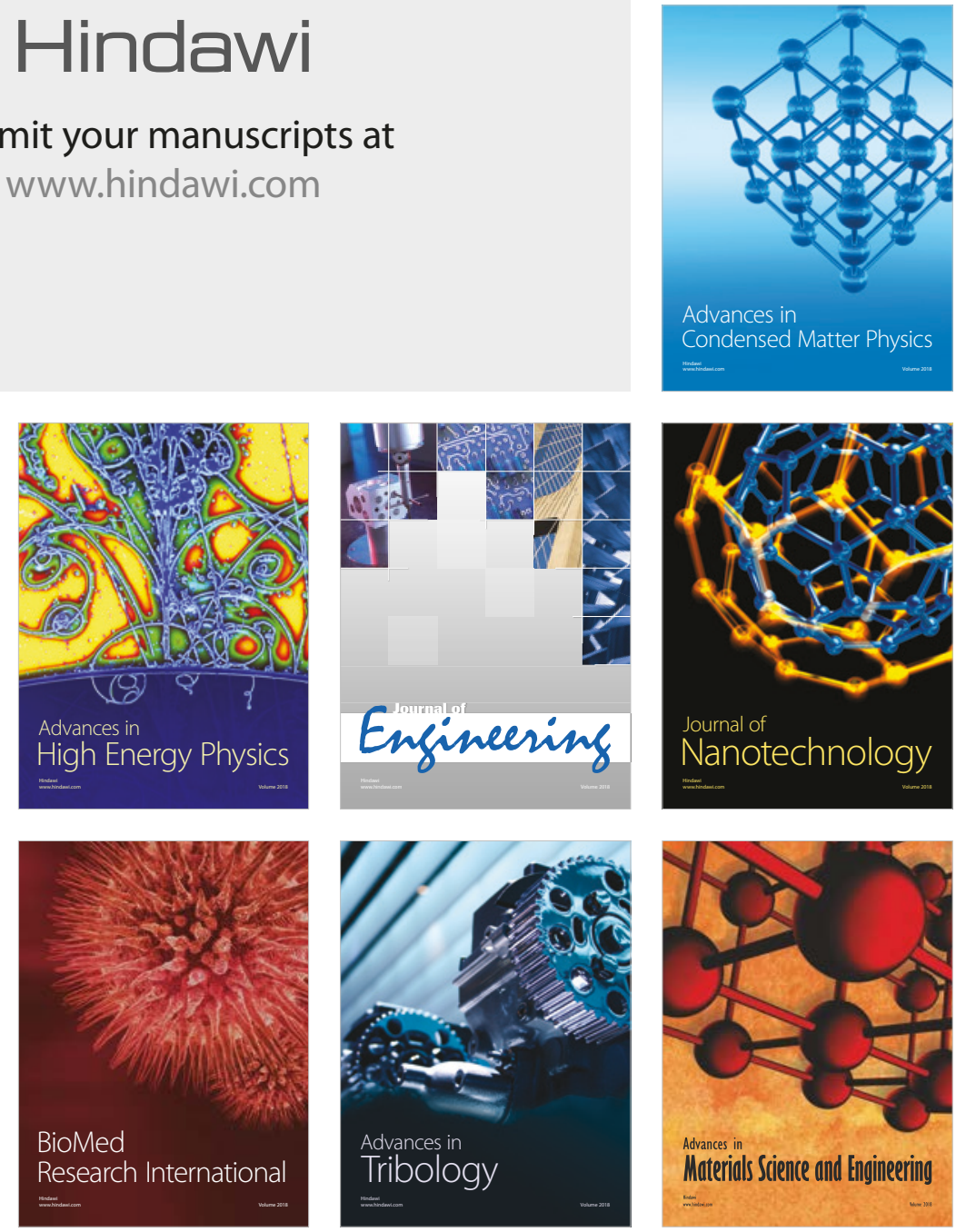